\title{
Retention and Transport of Silica Nanoparticles in Saturated Porous Media: Effect of Concentration and Particle Size
}

\author{
Chao Wang, ${ }^{\dagger}$ Aparna Devi Bobba, ${ }^{\dagger}$ Ramesh Attinti, $^{\dagger}$ Chongyang Shen, ${ }^{\ddagger}$ Volha Lazouskaya, ${ }^{\dagger}$ \\ Lian-Ping Wang, ${ }^{\S} *$ and Yan Jin ${ }^{\dagger, *}$ \\ ${ }^{\dagger}$ Department of Plant and Soil Sciences, University of Delaware, Newark, Delaware 19716, United States \\ ${ }^{\ddagger}$ Department of Soil and Water Sciences, China Agricultural University, Beijing 100094, China \\ ${ }^{\S}$ Department of Mechanical Engineering, University of Delaware, Newark, Delaware 19716, United States
}

\section{Supporting Information}

\begin{abstract}
Investigations on factors that affect the fate and transport of nanoparticles (NPs) remain incomplete to date. In the present study, we conducted column experiments using 8 and $52 \mathrm{~nm}$ silica NPs to examine the effects of NPs' concentration and size on their retention and transport in saturated porous media. Results showed that higher particle number concentration led to lower relative retention and greater surface coverage. Smaller NPs resulted in higher relative retention and lower surface coverage. Meanwhile, evaluation of size effect based on mass concentration $(\mathrm{mg} / \mathrm{L})$ vs particle number concentration (particles $/ \mathrm{mL}$ ) led to different conclusions. A set of equations for surface coverage calculation was developed and applied to explain the different

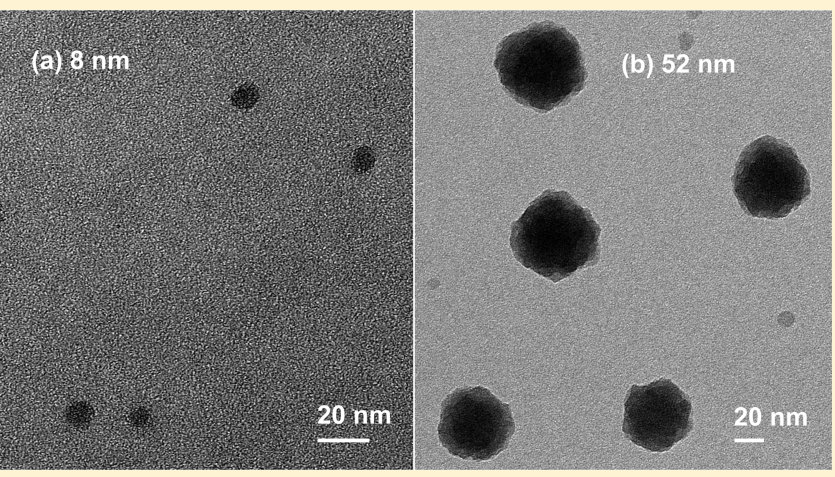
results related to the size effects when a given mass concentration $(\mathrm{mg} / \mathrm{L})$ and a given particle number concentration were used. In addition, we found that the retained $8 \mathrm{~nm}$ NPs were released upon lowered solution ionic strength, contrary to the prediction by the Derjaguin-Landau-Verwey-Overbeek (DLVO) theory. The study herein highlights the importance of NPs' concentration and size on their behavior in porous media. To the best of our knowledge, it is the first report of an improved equation for surface coverage calculation using column breakthrough data.
\end{abstract}

\section{INTRODUCTION}

The rapid growth of nanotechnology is giving rise to mass production and widespread application of NPs. ${ }^{1}$ During their production, application, and disposal, the NPs inevitably enter the environment. Because of their potential toxicity as well as their role as carriers for sorbed contaminants, the release of NPs may lead to environmental contamination.

Retention and transport of NPs in subsurface environment, especially in saturated porous media, has received considerable attention. For example, the retention and transport of manufactured $\mathrm{C}_{60}{ }^{2-12}$ carbon nanotubes, ${ }^{13-16}$ and oxide $\mathrm{NPs}^{2,17-25}$ in saturated porous media have been intensively studied. In these studies, factors that affect NPs' retention and transport have been evaluated, for example, flow velocity, ${ }^{2,18,20}$ NPs' surface potential, ${ }^{23}$ and presence of organic species. ${ }^{25,26}$ Nevertheless, the investigations to date are still largely incomplete. For instance, while the uniqueness of NPs (e.g., small size, large surface to volume ratio, and high reactivity) has been acknowledged, ${ }^{27}$ systematic study on the effect of particle size on NPs' environmental fate remains limited. ${ }^{22,28-31} \mathrm{~A}$ general conclusion from previous investigations on size effect using $\mathrm{TiO}_{2}$, aluminum, and $\mathrm{Fe}^{0} \mathrm{NPs}$ is that larger NPs have higher retention. ${ }^{22,23,28,31}$ Nonetheless, it is difficult to draw definite conclusions because $\mathrm{TiO}_{2}$, aluminum, and $\mathrm{Fe}^{0} \mathrm{NPs}$ are easily agglomerated, leading to size changes during transport ${ }^{27,32}$ and making it difficult to determine whether, how, and to what extent particle size played a role in their transport. Further investigation of NPs' size effect that uses relatively stable NPs is therefore necessary. On the other hand, Auffan et al. ${ }^{33}$ reported that inorganic NPs with sizes $<30 \mathrm{~nm}$ show different properties from those $>30 \mathrm{~nm}$ and proposed that the definition of NPs be modified from $1 \sim 100 \mathrm{~nm}$ to $1 \sim 30 \mathrm{~nm}$, whereas studies on NPs' environmental fate with stable sizes smaller than $30 \mathrm{~nm}$ are almost nonexistent.

Another factor that deserves more attention is the effect of particle concentration on NPs' retention and transport in porous media. The previous studies have demonstrated significant influence of input concentration on rates and retention mechanisms of micrometer-size particles (e.g., bacteria, latex, and aggregated $\mathrm{TiO}_{2}$ particles). ${ }^{20,34-37}$ Concentration effect of NPs, however, has not been fully evaluated. ${ }^{38,39}$ Studies that have

Received: February 3, 2012

Revised: $\quad$ May 23, 2012

Accepted: May 29, 2012

Published: May 29, 2012 
Table 1. Experimental Conditions, Deposition Rate Coefficients $\left(k_{\mathrm{d}}\right)$, Attachment Efficiencies $(\boldsymbol{\alpha})$, and Mass Recoveries of the Column Transport Experiments ${ }^{a}$

\begin{tabular}{|c|c|c|c|c|c|c|c|}
\hline $\begin{array}{l}\text { exp. } \\
\text { no. }\end{array}$ & $\begin{array}{l}\text { particle size } \\
\quad(\mathrm{nm})\end{array}$ & $\begin{array}{l}\text { input concentration } \\
\text { (particles } / \mathrm{mL})\end{array}$ & $\begin{array}{l}\text { ionic strength } \\
(\mathrm{mM})\end{array}$ & $\begin{array}{l}\text { water approach velocity } \\
\qquad(\mathrm{m} / \mathrm{s})\end{array}$ & $\begin{array}{c}\text { deposition rate } \\
\text { coefficient }^{b}\left(\mathrm{~h}^{-1}\right)\end{array}$ & $\begin{array}{l}\text { attachment } \\
\text { efficiency } \\
(\alpha)\end{array}$ & $\begin{array}{c}\text { mass recovery }^{c} \\
(\%)\end{array}$ \\
\hline 1 & 52 & $2.7 \times 10^{11}$ & 1 & $1.46 \times 10^{-5}$ & $(1.5 \pm 2.5) \times 10^{-2}$ & $(2.5 \pm 4.1) \times 10^{-4}$ & $98 \%$ \\
\hline 2 & 52 & $2.7 \times 10^{11}$ & 100 & $1.46 \times 10^{-5}$ & $(1.4 \pm 0.3) \times 10^{-1}$ & $(2.3 \pm 0.4) \times 10^{-3}$ & $90 \%$ \\
\hline 3 & 52 & $1.4 \times 10^{12}$ & 1 & $1.48 \times 10^{-5}$ & $(5.1 \pm 2.6) \times 10^{-2}$ & $(8.5 \pm 4.4) \times 10^{-4}$ & $95 \%$ \\
\hline 4 & 52 & $1.3 \times 10^{12}$ & 100 & $1.47 \times 10^{-5}$ & $(1.4 \pm 0.3) \times 10^{-1}$ & $(2.3 \pm 0.4) \times 10^{-3}$ & $91 \%$ \\
\hline 5 & 52 & $1.3 \times 10^{13}$ & 1 & $1.48 \times 10^{-5}$ & $(3.2 \pm 2.4) \times 10^{-2}$ & $(5.3 \pm 4.0) \times 10^{-4}$ & $98 \%$ \\
\hline 6 & 52 & $1.2 \times 10^{13}$ & 100 & $1.47 \times 10^{-5}$ & $(9.0 \pm 2.6) \times 10^{-2}$ & $(1.5 \pm 0.4) \times 10^{-3}$ & $93 \%$ \\
\hline 7 & 8 & $0.9 \times 10^{13}$ & 1 & $1.51 \times 10^{-5}$ & $(1.5 \pm 0.3) \times 10^{-1}$ & $(5.8 \pm 1.0) \times 10^{-4}$ & $89 \%$ \\
\hline 8 & 8 & $1.7 \times 10^{13}$ & 100 & $1.51 \times 10^{-5}$ & $(3.2 \pm 0.3) \times 10^{-1}$ & $(1.2 \pm 0.1) \times 10^{-3}$ & $85 \%$ \\
\hline 9 & 8 & $3.5 \times 10^{14}$ & 1 & $1.48 \times 10^{-5}$ & $(4.1 \pm 27) \times 10^{-3}$ & $(1.6 \pm 10) \times 10^{-5}$ & $100 \%$ \\
\hline 10 & 8 & $3.5 \times 10^{14}$ & 100 & $1.45 \times 10^{-5}$ & $(1.5 \pm 0.2) \times 10^{-1}$ & $(5.6 \pm 1.0) \times 10^{-4}$ & $92 \%$ \\
\hline 11 & 8 & $1.3 \times 10^{13}$ & 200 & $1.47 \times 10^{-5}$ & $(5.8 \pm 0.3) \times 10^{-1}$ & $(2.3 \pm 0.1) \times 10^{-3}$ & $57 \%$ \\
\hline
\end{tabular}

${ }^{a}$ Sands $(210 \mathrm{~g})$ were packed in each column with column porosity at $\sim 0.340$; solution $\mathrm{pH}$ was maintained at $10 .{ }^{b}$ “ \pm " represents the uncertainty of the value, based on $>9$ steady-state data points. ${ }^{c}$ Mass recovery was calculated as ratio of the number of NPs in effluent (phases 1 and 2 ) and the number of NPs in influent.

investigated effects of size used the same mass concentrations when comparing the behavior of differently sized NPs. ${ }^{22,28,31}$ It is not clear whether the comparison is conclusive because at the same mass concentration $(\mathrm{mg} / \mathrm{L})$, particle number concentration (particles $/ \mathrm{mL}$ ) can be orders of magnitude different when particles being compared span a wide size range. To date the potential implications of using mass or particle number concentrations in this type of studies on interpretation of particle size effect have not been adequately investigated. Similarly, standard protocols have not been developed to guide studies that examine the size-dependent toxicological behavior. For example, Simon-Deckers et al. ${ }^{40}$ evaluated NPs' size effect on the toxicity using the same mass concentration, but Jones et al. ${ }^{41}$ and Nair et al. ${ }^{42}$ performed the evaluation using the same particle number concentration. This makes comparison between different studies and interpretation of results difficult. Therefore, potential effect of concentrations, in terms of mass concentration and particle number concentration or namely appropriate concentration expression, needs to be systematically evaluated. Such information would be useful in the development and implementation of standard protocols for future investigations of NPs' environmental fate and toxicity.

Besides, most current theoretical description of NPs' retention and transport is limited to the classical filtration theory (CFT) ${ }^{43}$ supplemented by the $\mathrm{DLVO}^{44,45}$ force representations. ${ }^{3,5,7,9,15,22,46-50}$ For example, Li et al. ${ }^{7}$ investigated fullerene deposition and transport and observed that the effective collision efficiency was more than 1 order of magnitude larger than the value predicted by the DLVO theory. Conventional DLVO theory uses approximate expressions, for example, Derjaguin approximation $^{51}$ to represent electric double layer interaction. The assumptions under which the approximations hold, ${ }^{52}$ for example, $h \ll a_{\mathrm{p}}$ (i.e., separation distance is much less than NPs' radius) and $\kappa h \gg 1$ (i.e., separation distance is much larger than the Debye length), however, may not be applicable to small NPs. Because NPs, especially those with sizes $<20 \sim 30 \mathrm{~nm}$, may have unique properties (e.g., large specific surface area, exponentially increased surface atoms, and high interfacial reactivity) ${ }^{33}$ or are smaller than the thickness of electrical double layer, ${ }^{53}$ the applicability of the DLVO theory for describing their agglomeration, retention, and transport behavior has been questioned. $^{30}$
The objectives of this study were to (1) investigate effects of concentration and particle size on NPs' retention and transport in saturated porous media, and (2) examine the applicability of the DLVO theory to describe deposition of small NPs on sand surfaces. Because silica NPs are stable in suspension ${ }^{54,55}$ and thereby can be more easily controlled to have constant concentration and particle size, they were selected as representative NPs in the present study. In addition, the equations developed by Guzman et al. ${ }^{23}$ were used in order to calculate the DLVO interaction, considering that the equations exclude the Derjaguin approximation and thus do not need the assumptions of $h \ll a_{\mathrm{p}}$ and $\kappa h \gg 1$.

\section{MATERIALS AND METHODS}

Porous Media. A mixture of Accusands that is composed of $96.9 \% \mathrm{SiO}_{2}$ and $3.1 \% \mathrm{CaCO}_{3}$ with a mean diameter of $0.22 \mathrm{~mm}$ (Unimin, Le Sueur, MN) was used in this study. Before use, the sands were treated to remove metal oxides and other impurities, ${ }^{56,57}$ following the treatment procedure given in the Supporting Information (SI).

Silica NPs. Two monodispersed stock suspensions that contained surfactant-free silica NPs were purchased from the Nissan Chemical Industries, Ltd. (Tarrytown, NY). The mean diameters of silica NPs in the two suspensions are $8 \pm 2 \mathrm{~nm}$ and $52 \pm 1 \mathrm{~nm}$, respectively, based on measurements from transmission electron microscopy (TEM) images (see SI Figure $\mathrm{S} 1$ and experimental procedure for TEM imaging in the SI). The manufacturer reported densities of $8 \mathrm{~nm}$ and $52 \mathrm{~nm}$ NPs are 1.14 $\mathrm{g} / \mathrm{mL}$ and $1.30 \mathrm{~g} / \mathrm{mL}$, respectively. The silica NPs under the experimental conditions of the present study were stable, which was confirmed by dynamic light scattering (DLS) measurements of influent and effluents samples (Zetasizer Nano ZS, Malvern Instruments) and is consistent with literature reports. ${ }^{54,55}$ Electrophoretic mobilities of silica NPs were measured using a Zetasizer Nano ZS (Malvern Instruments) at $25 \pm 0.5^{\circ} \mathrm{C}, \mathrm{pH}=$ 10 , and with $50-2000 \mathrm{mg} / \mathrm{L}$ suspensions, which were then converted to zeta potentials (Table S1 in the SI) using the Henry Equation $^{58}$ (eq S1 in the SI).

Solution Chemistry. Deionized (DI) water and ACS grade $\mathrm{NaCl}$ were used for the preparation of background solutions at desired ionic strength (IS). Input NPs' suspensions were prepared by spiking the background solutions with NPs' stock suspensions and degassed thoroughly. Solution $\mathrm{pH}$ was there- 
after adjusted to 10 with $0.1 \mathrm{mM} \mathrm{NaHCO}$ and $0.1 \mathrm{mM} \mathrm{Na}_{2} \mathrm{CO}_{3}$ and subsequently using $0.01 \mathrm{M} \mathrm{HCl} / \mathrm{NaOH}$. We used $\mathrm{pH}$ as high as 10 in order to minimize surface charge heterogeneity and also to ensure attachment of silica NPs under unfavorable conditions. ${ }^{34,37}$

Column Transport Experiments. Column experiments were performed in a $10 \mathrm{~cm}$ long acrylic column (i.d. $=3.85 \mathrm{~cm}$ ) with similar column setups described elsewhere. ${ }^{56,59}$ A summary of experimental conditions are presented in Table 1. Briefly, during each experiment, $\sim 20 \mathrm{PVs}$ (pore volumes) of particle-free background solution was introduced upward to the column with a peristaltic pump. Background solution amended with bromide tracer $(\mathrm{KBr})$ was after that pumped to produce the breakthrough curves for the confirmation of consistency and reproducibility of the column packing (SI Figure S2) ${ }^{56}$ Experiments were thereafter run following a 3-phase procedure to differentiate primary- and secondary-minimum deposition. ${ }^{60}$ Successively, input solution was switched to silica NPs suspension (10 PVs, phase 1), background solution (4 PVs, phase 2), and DI water (6 PVs, phase 3). Samples of the effluent were collected from top of the column with a fraction collector. Column dissection was not performed, considering that the size ratios of silica NPs to media grains were an order of magnitude smaller than the reported 0.0017 threshold for straining to occur. ${ }^{61}$

Sample Analysis. Silica concentrations were measured by inductively coupled plasma-optical emission spectrometer (ICP-OES, Varian VISTA-MPX). Samples were diluted with acidified $\left(2 \% \mathrm{HNO}_{3}\right)$ background solution and the measured concentrations were corrected for background silica concentrations in controls (i.e., effluent samples of background buffer before introduction of silica NPs). The method detection limits were estimated $6.3 \times 10^{11}$ particles $/ \mathrm{mL}$ for $8 \mathrm{~nm}$ silica NPs and $2.0 \times 10^{9}$ particles $/ \mathrm{mL}$ for $52 \mathrm{~nm}$ silica NPs, respectively.

\section{THEORETICAL CONSIDERATION}

Deposition Rate Coefficient $\left(\boldsymbol{k}_{\mathrm{d}}\right)$ and Attachment Efficiency $(\boldsymbol{\alpha})$. The deposition rate coefficient $\left(k_{\mathrm{d}}, \mathrm{h}^{-1}\right)$ is determined by the following equation: ${ }^{43,56,62}$

$$
k_{\mathrm{d}}=\frac{v_{\mathrm{p}}}{L} \ln \left(\frac{C_{0}}{C}\right)
$$

where $v_{\mathrm{p}}$ is pore water velocity $(\mathrm{cm} / \mathrm{min}), L$ is column length (cm), $C_{0}$ is input NPs' number concentration (particles $/ \mathrm{mL}$ ), and $C$ is effluent NPs' concentration (particles $/ \mathrm{mL}$ ) which was represented by steady-state concentration, $C_{s}$ (particles $\left./ \mathrm{mL}\right)$, in the present study. ${ }^{9,22,63}$

The obtained $k_{\mathrm{d}}$ was then used to calculate the attachment efficiency $(\alpha)$ using the following equation: ${ }^{56,62}$

$$
\alpha=\frac{4 k_{\mathrm{d}} a_{\mathrm{c}}}{3(1-\varepsilon) v_{\mathrm{p}} \eta_{0}}
$$

where $a_{\mathrm{c}}$ is mean collector radius (mm), $\varepsilon$ is column porosity, $\eta_{0}$ is single collector efficiency, which is determined by the following correlation equation: ${ }^{62}$

$$
\begin{aligned}
\eta_{0}= & 2.4 A_{\mathrm{S}}^{1 / 3} N_{\mathrm{R}}^{-0.081} N_{\mathrm{Pe}}^{-0.715} N_{\mathrm{vdW}}^{0.052}+0.55 A_{\mathrm{S}} N_{\mathrm{R}}^{1.55} N_{\mathrm{Pe}}^{-0.125} \\
& N_{\mathrm{vdW}}^{0.125}+0.22 N_{\mathrm{R}}^{-0.24} N_{\mathrm{G}}^{1.11} N_{\mathrm{vdW}}^{0.053}
\end{aligned}
$$

where $A_{\mathrm{S}}$ is a porosity-dependent parameter, $N_{\mathrm{R}}$ is aspect ratio, $N_{\mathrm{Pe}}$ is Peclet number, $N_{\mathrm{vdW}}$ is van der Waals number, and $N_{\mathrm{G}}$ is gravitational number.
Surface Coverage $(\boldsymbol{\theta})$. Surface coverage was computed from a breakthrough curve, using the following equation: ${ }^{64-66}$

$$
\theta=\frac{\pi a_{\mathrm{p}}^{2} U a_{\mathrm{c}} C_{0} \int_{0}^{t}\left(1-\frac{c}{C_{0}}\right) \mathrm{d} t}{3 L(1-\varepsilon)}
$$

where $a_{\mathrm{p}}$ is particle radius $(\mathrm{nm}), U$ is water approach (Darcy) velocity $(\mathrm{cm} / \mathrm{min})$, and $t$ is duration of time for phase 1 breakthrough experiment $(\mathrm{min})$.

The above equation (see derivation of eq $4 \mathrm{a}$ in the SI) calculates surface coverage using the total loaded particles in the column at any given time, which includes both the suspended particles in pore water and the attached ones on collector surfaces and thereby overestimates surface coverage. The overestimation would be significant when $C_{0}$ is high and especially the suspended particles in pore water account for a significant portion of all the particles in the column. To correct such an overestimation, eq $4 \mathrm{~b}$ is developed (see derivation of eq $4 \mathrm{~b}$ in the $\mathrm{SI}$ ) to calculate the corrected surface coverage:

$$
\theta=\left\{\begin{array}{l}
\frac{\pi a_{\mathrm{p}}^{2} a_{c} C_{0} v_{\mathrm{p}} \varepsilon}{3 L(1-\varepsilon)}\left[\int_{0}^{t}\left(1-\frac{C}{C_{0}}\right) \mathrm{d} t \text { for } \mathrm{PV}<1\right. \\
-\frac{1}{k_{\mathrm{d}}}\left(1-e^{\left.\left.-\mathrm{PV} \frac{k_{d} \mathrm{~L}}{v_{\mathrm{p}}}\right)\right],}\right. \\
\frac{\pi a_{\mathrm{p}}^{2} a_{\mathrm{c}} C_{0} v_{\mathrm{p}} \varepsilon}{3 L(1-\varepsilon)}\left[\int_{0}^{t}\left(1-\frac{C}{C_{0}}\right) \mathrm{d} t \text { for } \mathrm{PV} \geq 1\right. \\
\left.\quad-\frac{1}{k_{\mathrm{d}}}\left(1-e^{-\frac{k_{\mathrm{d}} L}{v_{\mathrm{p}}}}\right)\right],
\end{array}\right.
$$

where PV is pore volume. Figure S3 in the SI shows that after the correction the surface coverage was significantly reduced in the present study.

Equation $4 \mathrm{~b}$ can be further written as follows with several approximations (see Derivation of eqs $4 \mathrm{c}$ and $4 \mathrm{~d}$ in the SI):

$$
\theta= \begin{cases}\left(\pi a_{\mathrm{p}}^{2} k_{\mathrm{d}} C_{0}\right) \frac{a_{\mathrm{c}} \varepsilon}{3(1-\varepsilon)} \frac{L}{v_{\mathrm{p}}} \frac{\mathrm{PV}^{2}}{2}, & \text { for PV }<1 \\ \left(\pi a_{\mathrm{p}}^{2} k_{\mathrm{d}} C_{0}\right) \frac{a_{\mathrm{c}} \varepsilon}{3(1-\varepsilon)} \frac{L}{v_{\mathrm{p}}}\left(\mathrm{PV}-\frac{1}{2}\right), & \text { for PV } \geq 1\end{cases}
$$

or

$$
\theta= \begin{cases}m_{0} \frac{a_{\mathrm{c}} \varepsilon}{4(1-\varepsilon) a_{\mathrm{p}} \rho} \frac{k_{\mathrm{d}} L}{v_{\mathrm{p}}} \frac{\mathrm{PV}^{2}}{2}, & \text { for } \mathrm{PV}<1 \\ m_{0} \frac{a_{\mathrm{c}} \varepsilon}{4(1-\varepsilon) a_{\mathrm{p}} \rho} \frac{k_{\mathrm{d}} L}{v_{\mathrm{p}}}\left(\mathrm{PV}-\frac{1}{2}\right), & \text { for } \mathrm{PV} \geq 1\end{cases}
$$

where $m_{0}\left[=(4 / 3) \pi a_{\mathrm{p}}^{3} \rho C_{0}\right]$ is input mass concentration $(\mathrm{mg} / \mathrm{L})$ and $\rho$ is NP's density $(\mathrm{g} / \mathrm{mL})$. Equation $4 \mathrm{c}$ states that $\theta$ is proportional to $\pi a_{\mathrm{p}}^{2} k_{\mathrm{p}} C_{0}$ and eq $4 \mathrm{~d}$ indicates that $\theta$ is proportional to $\left(k_{\mathrm{d}} / a_{\mathrm{p}}\right)$ for a given mass concentration $\left(m_{0}\right)$.

Additionally, when using the concept of surface coverage, assumptions (1) particles form monolayer coverage on collector surfaces and (2) no particle detachment occurs during deposition processes, are generally made. ${ }^{11,67}$ These assumptions are likely valid in the present study for the following reasons. First, silica NPs used in this study had same particle-size distributions before and after experiments, as indicated by DLS measurements, 
consistent with reports in the literature that silica NPs are stable in suspension. ${ }^{54,55}$ Second, breakthrough curves reached stable plateau concentrations, suggesting the lack of ripening effects (Figure 1a-d). Third, there was little particle detachment as indicated by the negligible tailing during flushing with particlefree solution (phase 2) $)^{50,68}$ (Figure $1 \mathrm{a}-\mathrm{d}$ ).

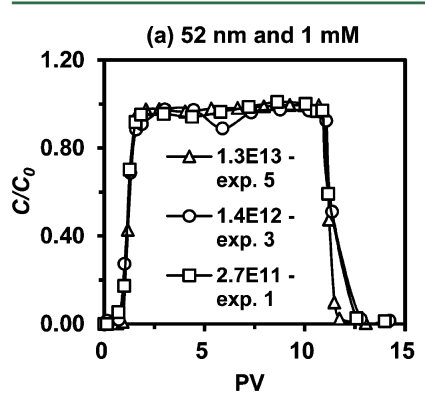

(c) $52 \mathrm{~nm}$ and $100 \mathrm{mM}$

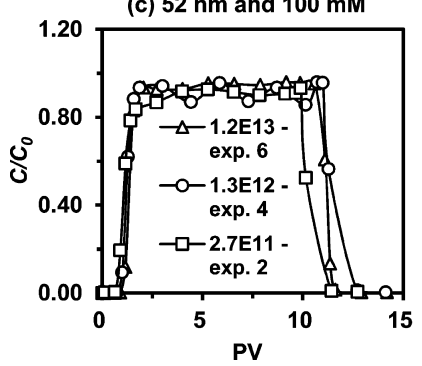

(b) $8 \mathrm{~nm}$ and $1 \mathrm{mM}$

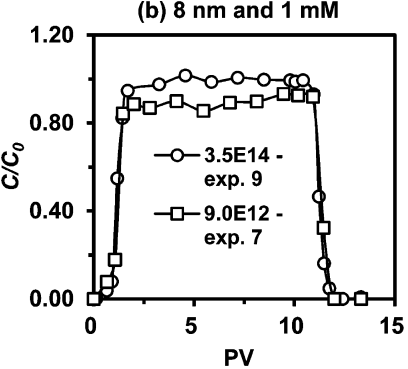

(d) $8 \mathrm{~nm}$ and $100 \mathrm{mM}$

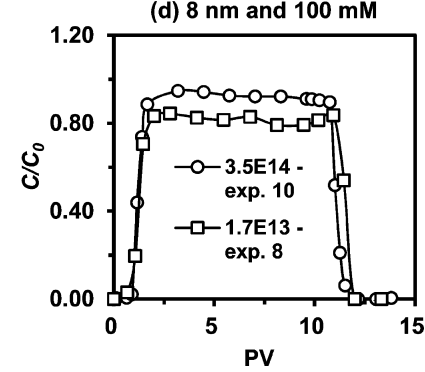

Figure 1. Concentration $\left(C_{0}\right)$ effect on retention of $52 \mathrm{~nm}$ and $8 \mathrm{~nm}$ silica NPs: (a) $52 \mathrm{~nm}$ and IS $=1 \mathrm{mM}$, (b) $8 \mathrm{~nm}$ and IS $=1 \mathrm{mM}$, (c) 52 $\mathrm{nm}$ and IS $=100 \mathrm{mM}$, and (d) $8 \mathrm{~nm}$ and IS $=100 \mathrm{mM}$.

DLVO Interactions. The DLVO interaction energy $\left(\Phi_{\text {DLVO }}\right.$ $\mathrm{J}$ ) between NPs and collectors, which is regarded as sphere-plate interaction, is a sum of the double-layer repulsion $\left(\Phi_{\mathrm{el}} \mathrm{J}\right)$ and retarded van der Waals attraction $\left(\Phi_{\mathrm{vdW}}, \mathrm{J}\right):^{23}$

$$
\Phi_{\mathrm{DLVO}}=\Phi_{\mathrm{el}}+\Phi_{\mathrm{vdW}}
$$

where

$$
\begin{aligned}
& \Phi_{\mathrm{el}}=\pi \varepsilon_{0} \varepsilon_{r} \kappa\left(\psi_{\mathrm{s}}^{2}+\psi_{\mathrm{p}}^{2}\right) \\
& \int_{0}^{a_{\mathrm{p}}}\left(\begin{array}{l}
-\operatorname{coth}\left[\kappa\left(h+a_{\mathrm{p}}-a_{\mathrm{p}} \sqrt{1-\left(r / a_{\mathrm{p}}\right)^{2}}\right)\right] \\
+\operatorname{coth}\left[\kappa\left(h+a_{\mathrm{p}}+a_{\mathrm{p}} \sqrt{1-\left(r / a_{\mathrm{p}}\right)^{2}}\right)\right] \\
+\frac{\left(2 \psi_{\mathrm{s}} \psi_{\mathrm{p}}\right)}{\left(\psi_{\mathrm{s}}^{2}+\psi_{\mathrm{p}}^{2}\right)} \csc h\left[\kappa \left(h+a_{\mathrm{p}}\right.\right. \\
\left.\left.-a_{\mathrm{p}} \sqrt{1-\left(r / a_{\mathrm{p}}\right)^{2}}\right)\right] \\
-\frac{\left(2 \psi_{\mathrm{s}} \psi_{\mathrm{p}}\right)}{\left(\psi_{\mathrm{s}}^{2}+\psi_{\mathrm{p}}^{2}\right)} \csc h\left[\kappa \left(h+a_{\mathrm{p}}\right.\right. \\
\left.\left.+a_{\mathrm{p}} \sqrt{1-\left(r / a_{\mathrm{p}}\right)^{2}}\right)\right]
\end{array}\right) \mathrm{rdr} \\
& \Phi_{\mathrm{vdW}}=-\frac{A}{6}\left[\frac{a_{\mathrm{p}}}{h}+\frac{a_{\mathrm{p}}}{h+2 a_{\mathrm{p}}}+\ln \left(\frac{h}{h+2 a_{\mathrm{p}}}\right)\right]
\end{aligned}
$$

where $\varepsilon_{0}$ is free space permittivity $(\mathrm{F} / \mathrm{m}), \varepsilon_{\mathrm{r}}$ is relative permittivity, $\kappa$ is inverse of Debye length $\left(\mathrm{nm}^{-1}\right)$ (see eq $\mathrm{S} 2$ in the SI), $\psi_{\mathrm{s}}$ and $\psi_{\mathrm{p}}$ are surface potentials of sphere and plate, respectively, and are usually approximated as zeta-potentials, ${ }^{52} \mathrm{~h}$ is minimum surface-to-surface separation distance $(\mathrm{nm})$, and $A$ is nonretarded Hamaker constant $\left(=6.3 \times 10^{-21} \mathrm{~J}\right){ }^{69,70}$ Equations 6 and 7 were developed by Guzman et al. ${ }^{23}$ with surface element integration technique, ${ }^{71}$ which exclude Derjaguin approximation and thus do not need the assumptions of $h \ll a_{\mathrm{p}}$ and $\kappa h \gg 1$.

\section{RESULTS AND DISCUSSION}

Concentration Effect. Concentration effect of silica NPs on their transport in saturated porous media was evaluated at IS of 1 $\mathrm{mM}$ and $100 \mathrm{mM}$ over a concentration range from $10^{11}$ to $10^{14}$ particles $/ \mathrm{mL}$ (Table 1 ), which are within colloidal concentration range used in relevant studies. ${ }^{72}$ Breakthrough curves (BTCs) of silica NPs, that is, relative effluent concentration $\left(C / C_{0}\right)$ as a function of PV, are plotted in Figure 1a-d. The BTCs of $8 \mathrm{~nm}$ NPs (Figure $1 \mathrm{~b}$ and $\mathrm{d}$ ) show that the values of steady-state effluent concentrations $\left(C_{\mathrm{s}} / C_{0}\right)$ increased with $C_{0}$ at both IS values, suggesting that higher $C_{0}$ gave rise to lower relative retention. On the other hand, the values of $C_{\mathrm{s}} / C_{0}$ in the BTCs of $52 \mathrm{~nm}$ NPs reached close to 1.0 (Figure 1a and c), implying that the retention capacity of the porous media for $52 \mathrm{~nm}$ NPs was low. Because the differences in the breakthrough curves with respect to $52 \mathrm{~nm}$ NPs are so small, which was caused by the limited retention capacity of the porous media for the $52 \mathrm{~nm}$ silica NPs, a definite evaluation of concentration effect on the BTCs was not allowed in this case.

Additionally, we evaluated concentration effect on surface coverage $(\theta)$ of silica NPs using eq $4 b$. Figure $2 a-d$ demonstrates
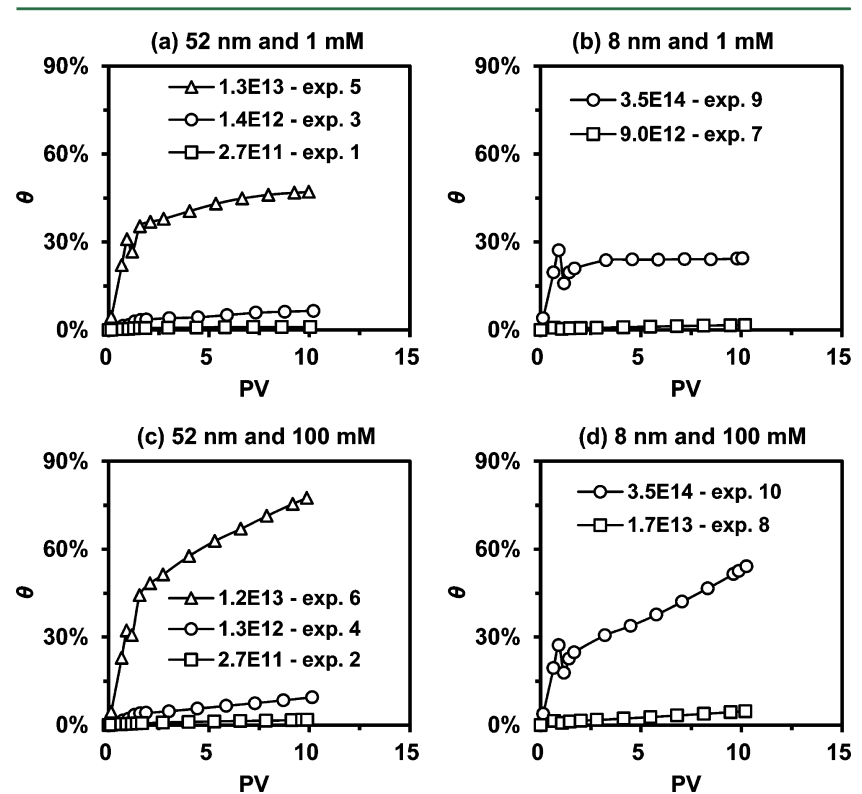

Figure 2. Concentration $\left(C_{0}\right)$ effect on surface coverage $(\theta)$ of $52 \mathrm{~nm}$ and $8 \mathrm{~nm}$ silica NPs: (a) $52 \mathrm{~nm}$ and IS $=1 \mathrm{mM}$, (b) $8 \mathrm{~nm}$ and IS $=1 \mathrm{mM}$, (c) $52 \mathrm{~nm}$ and IS $=100 \mathrm{mM}$, and (d) $8 \mathrm{~nm}$ and IS $=100 \mathrm{mM}$.

that higher $C_{0}$ contributed to larger $\theta$ at both IS of 1 and $100 \mathrm{mM}$. This observation is supported by eq $4 \mathrm{c}$, which shows that surface coverage is proportional to $C_{0}$. To further evaluate the concentration effect, we calculated the deposition rate coefficient $\left(k_{\mathrm{d}}\right)$ and attachment efficiency $(\alpha)$ using measured $C_{\mathrm{s}} / C_{0}$ values and eqs 1 and 2 . Table 1 shows that a definite trend of the dependence of $k_{\mathrm{d}}$ and $\alpha$ on $C_{0}$ is not available to the present cases. 
Results from this study are generally consistent with literature reports based on studies with micrometer-sized particles (e.g., latex microspheres, bacteria cells, and aggregated $\mathrm{TiO}_{2}$ particles). ${ }^{18,35-37}$ Bradford and colleagues ${ }^{36,37}$ hypothesized that the concentration-dependent colloid retention and transport are due to (i) concentration-dependent filling of retention sites and (ii) concentration-dependent mass transfer of colloids to retention sites. At present, studies of concentration effect on retention and transport of NPs are very limited. ${ }^{38,39}$ Our study indicates that these proposed mechanisms may also apply to explain the behavior of very small NPs. Additionally, it was once reported that greater input concentrations resulted in increased relative colloidal retention at IS $>0.1 \mathrm{mM},{ }^{34}$ which is opposite to the present results, attributing to the ripening effect. ${ }^{34}$ Since the silica NPs used in the present study were stable, ripening should be insignificant in the present cases.

The above discussion suggests that it is important to pay attention to the concentration effects when comparing results from different studies. Moreover, interpretation of experimental results involving different concentrations becomes more complex when the key focus of the studies is to identify differences between NPs and their larger counterparts. The additional complexity may arise from inconsistent use of mass or particle number concentrations. We address the interplay between particle size and concentration effects in detail in Size Effect section below.

Size Effect. The breakthrough curves in Figure $3 a$ and $b$ shows that the relative retention was higher for $8 \mathrm{~nm}$ NPs than

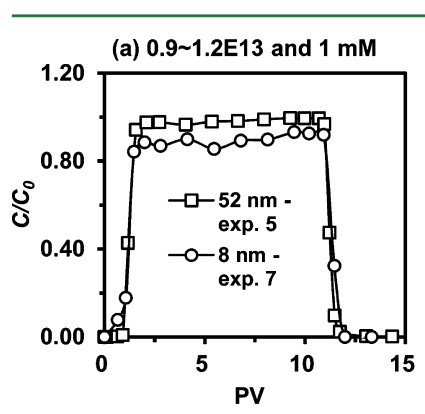

(c) $0.9 \sim 1.2 \mathrm{E} 13$ and $1 \mathrm{mM}$

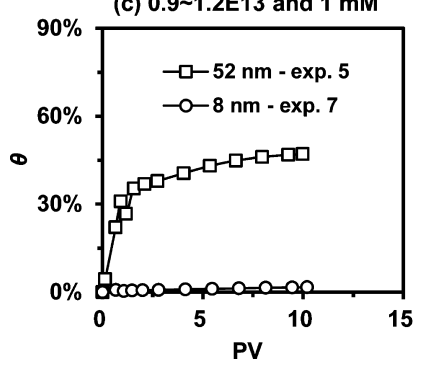

(b) 1.2 1.7E13 and $100 \mathrm{mM}$

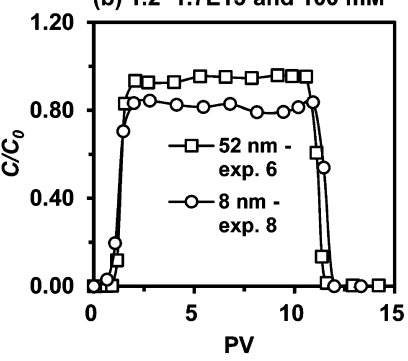

(d) 1.2 1.7E13 and $100 \mathrm{mM}$

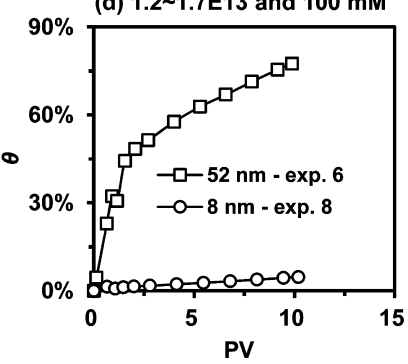

Figure 3. Size effect on retention of silica NPs: (a) IS $=1 \mathrm{mM}$ and (b) IS $=100 \mathrm{mM}$ and on surface coverage $(\theta)$ of silica NPs: (c) IS $=1 \mathrm{mM}$ and (d) IS $=100 \mathrm{mM}$. Comparisons are performed under the same particle number concentrations.

for $52 \mathrm{~nm}$ NPs at both 1 and $100 \mathrm{mM}$ IS. On the other hand, Table 1 indicates that $8 \mathrm{~nm}$ NPs have larger $k_{\mathrm{d}}$ values than $52 \mathrm{~nm}$ NPs at both 1 and $100 \mathrm{mM}$ IS (exp. 7 vs exp. 5 and exp. 8 vs exp. 6 , respectively). These results suggest that, at the same particle number concentration, the smaller $8 \mathrm{~nm}$ NPs would deposit faster. There are likely two mechanisms that are responsible for the observed size effect. First, size affects directly the interaction energies between NPs and sand surfaces, as shown by eqs 6 and 7 .
Second, size affects NPs physical and/or chemical properties, for example, zeta-potential as shown in SI Table S1, and thereby indirectly and further affects the interaction energies. In both mechanisms, size is the origin to the observed different retention and transport behaviors.

Table 1 also shows that the attachment efficiencies $(\alpha)$ of $8 \mathrm{~nm}$ NPs were almost similar to that of $52 \mathrm{~nm}$ NPs at the two IS values (exp. 7 vs exp. 5 and exp. 8 vs exp. 6). The results indicate that faster deposition rate is not a guarantee for higher attachment efficiency, because attachment efficiency is determined by both the deposition rate coefficient $\left(k_{\mathrm{d}}\right)$ and collector contact efficiency $\left(\eta_{0}\right)$, not by $k_{\mathrm{d}}$ alone (see eq 2 ). In addition, Figure $3 \mathrm{c}$ and demonstrates that, at both IS values, the smaller $8 \mathrm{~nm}$ NPs had lower surface coverages. This is reasonable because, at the same particle number concentration $\left(C_{0}\right)$, smaller particles have much smaller total projection area $\left(\pi a_{\mathrm{p}}^{2}\right)$ than the larger ones (see eq 4c).

Analyses of the results from this study also reveal that, interpretation of size effect on NPs' retention and transport would lead to different conclusions, depending on whether the interpretation was based on mass concentration $(\mathrm{mg} / \mathrm{L})$ or particle number concentration (particles/mL). For example, under similar particle number concentrations, the larger NPs (52 $\mathrm{nm}$ ) had lower relative retention, but higher surface coverage (Figure $3 a-d$ ) than the smaller NPs, whereas under similar mass concentrations, relative retention of both $52 \mathrm{~nm}$ and $8 \mathrm{~nm}$ NPs was similar but the smaller NPs had higher surface coverage (Figure S4a-d in the SI). The discrepancy suggests that, when studies are conducted with the goal to reveal potential behavior of NPs relative to their larger counterparts (both on environmental fate and toxicity), special attention should be paid to the potential effect of concentrations, in terms of mass concentration and particle number concentration or namely appropriate concentration expression. In fact, the apparent discrepancy can be explained by eqs $4 \mathrm{c}$ and $4 \mathrm{~d}$. Equation $4 \mathrm{c}$ shows that, for a given particle number concentration $\left(C_{0}\right), \theta$ can be higher for larger NPs because it is proportional to $\pi a_{\mathrm{p}}^{2} k_{\mathrm{d}} C_{0}$, if the $k_{\mathrm{d}}$ value does not decrease a lot in comparison to that of the increase in $a_{\mathrm{p}}^{2}$, which is true according to Table 1 . Meanwhile, eq $4 \mathrm{~d}$ indicates that, for a given mass concentration $\left(m_{0}\right), \theta$ is higher for smaller NPs, where the $k_{\mathrm{d}}$ value is similar according to eq 1 because of the nearly identical $C_{\mathrm{s}} / C_{0}$. We believe that using particle number concentration as the basis for comparisons of NPs' fate and toxicity may provide additional insights. In aerosol research, it has been reported that surface area and particle number concentrations are better predictors than mass concentrations of risks associated with NPs' exposure and toxicity in air. ${ }^{38,39}$

The above results demonstrate that the smaller NPs ( $8 \mathrm{~nm}$ vs $52 \mathrm{~nm}$ ) corresponded to higher relative retention, faster deposition, and lower surface coverage. These results are contrary to the previous reports that the smaller NPs (e.g., $\mathrm{TiO}_{2}$, aluminum, and $\mathrm{Fe}^{0} \mathrm{NPs}$ ) had less relative retention. ${ }^{22,23,28,31}$ This could be because the comparison was made previously based on the same NPs' mass concentration. In addition, it is likely that particle size was not well controlled due to agglomeration, leading to particle size and particle number concentration change during the experiments. As such, it is difficult to make a definite evaluation on the effect of NPs' size in those studies.

Applicability of DLVO Theory. The results in Figure 4a and b show that both $8 \mathrm{~nm}$ and $52 \mathrm{~nm}$ silica NPs were released upon introduction of DI water during phase 3 (from 14 to $20 \mathrm{PVs}$ ). However, the release of $8 \mathrm{~nm}$ silica NPs was much more 

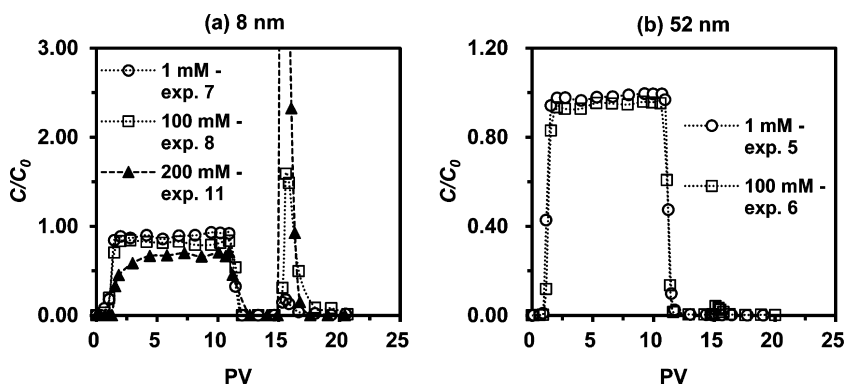

Figure 4. Reversibility of deposition of (a) $8 \mathrm{~nm}$ and (b) $52 \mathrm{~nm}$ silica NPs under various IS.

pronounced than $52 \mathrm{~nm}$ particles. Mass balance analysis indicated that $\sim 100 \%$ of the deposited $8 \mathrm{~nm}$ silica NPs at IS = $100 \mathrm{mM}$ was released, whereas the release of $52 \mathrm{~nm}$ NPs was $\sim 2 \%$.

The limited release of $52 \mathrm{~nm}$ silica NPs can be explained by the DLVO theory. According to the DLVO calculation, the depths of secondary energy minima $\left(\Phi_{\text {sec }}\right)$ are in the range of $0-1.4 \mathrm{kT}$ (Table 2). These $\Phi_{\text {sec }}$ values are smaller than the average kinetic

Table 2. Calculated Maximum Energy Barriers $\left(\boldsymbol{\Phi}_{\max }\right)$, Secondary Energy Minimum Depths $\left(\Phi_{\text {sec }}\right)$, and their Respective Separation Distances of DLVO Interaction Profiles between Silica NPs and Sands ${ }^{a}$

\begin{tabular}{|c|c|c|c|c|c|c|c|c|}
\hline \multirow[b]{3}{*}{$(\mathrm{mM})$} & \multicolumn{4}{|c|}{$\Phi_{\max }$} & \multicolumn{4}{|c|}{$\Phi_{\mathrm{sec}}$} \\
\hline & \multicolumn{2}{|c|}{ height $(\mathrm{kT})$} & \multicolumn{2}{|c|}{ distance $(\mathrm{nm})$} & \multicolumn{2}{|c|}{ depth (kT) } & \multicolumn{2}{|c|}{ distance $(\mathrm{nm})$} \\
\hline & $8 \mathrm{~nm}$ & $52 \mathrm{~nm}$ & $8 \mathrm{~nm}$ & $52 \mathrm{~nm}$ & $8 \mathrm{~nm}$ & $52 \mathrm{~nm}$ & $8 \mathrm{~nm}$ & $52 \mathrm{~nm}$ \\
\hline 1 & 0.3 & 101.4 & 5.3 & 1.6 & 0 & 0 & $\rho^{b}$ & $j^{b}$ \\
\hline 100 & 1.8 & 30.8 & 0.6 & 0.5 & 0 & 1.4 & $j^{b}$ & 5.6 \\
\hline 200 & 1.1 & $\mathrm{~N} / \mathrm{A}^{c}$ & 0.6 & $\mathrm{~N} / \mathrm{A}^{c}$ & 0 & $\mathrm{~N} / \mathrm{A}^{c}$ & $j^{b}$ & $\mathrm{~N} / \mathrm{A}^{c}$ \\
\hline
\end{tabular}

${ }^{a}$ Hamaker constant is $6.3 \times 10^{-21} \mathrm{~J}^{69,70}$ and $\mathrm{pH}=10 .{ }^{b} \Phi_{\text {sec }}$ does not exist. ${ }^{c}$ None available.

energy (1.5 kT) associated with particles' Brownian motion, ${ }^{60,73}$ therefore, limited retention in and release from the secondary energy minima is expected for $52 \mathrm{~nm}$ NPs. On the other hand, the significant release of $8 \mathrm{~nm}$ silica NPs is inconsistent with the DLVO prediction. This is because the DLVO calculation suggests likelihood of primary minimum deposition (due to low energy barrier heights) rather than retention in secondary minima (due to minimal $\Phi_{\mathrm{sec}}$ values) (Table 2), whereas the experimental observation of the significant release indicates that there was large deposition of $8 \mathrm{~nm}$ NPs in the secondary energy minima.

The above results clearly indicate that the DLVO theory is not applicable to describe the behavior of $8 \mathrm{~nm}$ NPs. This might be that, in addition to the double layer repulsion and van der Waals attraction, other short-range interactions (e.g., hydration and solvation) may also play an important role, resulting in the failure of the DLVO prediction. Hahn and O'Melia ${ }^{73}$ have pointed out that the release of deposited particles can occur at separation distances of a few nanometers where the DLVO theory usually is not able to provide a quantitative description due to significant contribution of other types of interactions. On the other hand, when NPs are very small so that the overlap of diffuse double layers is complete, DLVO theory may not be valid; rather, the Brønsted concept based on the Transitional State theory of interacting ions has been applied. ${ }^{53}$ In addition, our recent study ${ }^{74}$ indicated that surface roughness, mainly in the form of large valleys on sand grains, can locally increase the energy barrier as well as depth of the secondary energy minima, which would allow additional retention of particles in the secondary energy minima. Moreover, we found that the asperities on sand surfaces would shield depositing particles from hydrodynamic shear from being detached. Both roughness effects might be also responsible for the significant reversible release of $8 \mathrm{~nm}$ NPs as was observed during the phase 3 experiments.

While mechanisms for the failure of the DLVO theory to very small NPs may need to be systematically studied further, the above results in Figure $4 \mathrm{a}$ and $\mathrm{b}$ suggest that careful experimental scrutiny on NPs release from the porous media is quite necessary, especially when the size reduces to very small value (e.g., $8 \mathrm{~nm}$ in this case). Pronounced release of deposited NPs in porous media may occur upon lowering of pore water IS (e.g., in the event of rainfall), which is not predicted by the DLVO theory but could exert severe environmental consequences.

\section{ASSOCIATED CONTENT}

\section{Supporting Information}

Additional material as noted in the text. This information is available free of charge via the Internet at http://pubs.acs.org/.

\section{AUTHOR INFORMATION}

\section{Corresponding Author}

*Phone: (302)831-6962 (Y. J.); (302)831-8160 (L. P. W.). Fax: (302)831-0605 (Y. J.); (302)831-3619 (L. P.W.). E-mail: yjin@ udel.edu (Y. J.); lwang@udel.edu (L. P. W.).

\section{Notes}

The authors declare no competing financial interest.

\section{ACKNOWLEDGMENTS}

This research was supported by the National Research Initiative Competitive Grant (No. 2001-35107-01235) from the USDA Cooperative State Research, Education, and Extension Services, the Star Project (R833318) from the U.S. EPA, the National Science Foundation under grants CBET-0932686 and EAR0207788 (C.S.W.), and the National Natural Science Foundation of China (No. 40901109).

\section{REFERENCES}

(1) Wiesner, M. R.; Lowry, G. V.; Alvarez, P.; Dionysiou, D.; Biswas, P. Assessing the risks of manufactured nanomaterials. Environ. Sci. Technol. 2006, 40 (14), 4336-4345.

(2) Lecoanet, H. F.; Wiesner, M. R. Velocity effects on fullerene and oxide nanoparticle deposition in porous media. Environ. Sci. Technol. 2004, 38 (16), 4377-4382.

(3) Brant, J.; Lecoanet, H.; Wiesner, M. R. Aggregation and deposition characteristics of fullerene nanoparticles in aqueous systems. J. Nanopart. Res. 2005, 7 (4-5), 545-553.

(4) Chen, K. L.; Elimelech, M. Aggregation and deposition kinetics of fullerene $\left(C_{60}\right)$ nanoparticles. Langmuir 2006, 22 (26), 10994-11001.

(5) Espinasse, B.; Hotze, E. M.; Wiesner, M. R. Transport and retention of colloidal aggregates of $\mathrm{C}_{60}$ in porous media: Effects of organic macromolecules, ionic composition, and preparation method. Environ. Sci. Technol. 2007, 41 (21), 7396-7402.

(6) Chen, K. L.; Elimelech, M. Interaction of fullerene $\left(\mathrm{C}_{60}\right)$ nanoparticles with humic acid and alginate coated silica surfaces: Measurements, mechanisms, and environmental implications. Environ. Sci. Technol. 2008, 42 (20), 7607-7614.

(7) Li, Y. S.; Wang, Y. G.; Pennell, K. D.; Abriola, L. M. Investigation of the transport and deposition of fullerene $\left(\mathrm{C}_{60}\right)$ nanoparticles in quartz sands under varying flow conditions. Environ. Sci. Technol. 2008, 42 (19), 7174-7180. 
(8) Wang, Y. G.; Li, Y. S.; Fortner, J. D.; Hughes, J. B.; Abriola, L. M.; Pennell, K. D. Transport and retention of nanoscale $\mathrm{C}_{60}$ aggregates in water-saturated porous media. Environ. Sci. Technol. 2008, 42 (10), 3588-3594.

(9) Wang, Y. G.; Li, Y. S.; Pennell, K. D. Influence of electrolyte species and concentration on the aggregation and transport of fullerene nanoparticles in quartz sands. Environ. Toxicol. Chem. 2008, 27 (9), 1860-1867.

(10) Tong, M.; Ding, J.; Shen, Y.; Zhu, P. Influence of biofilm on the transport of fullerene $\left(\mathrm{C}_{60}\right)$ nanoparticles in porous media. Water Res. 2010, 44 (4), 1094-1103.

(11) Wang, Y. G.; Li, Y. S.; Kim, H.; Walker, S. L.; Abriola, L. M.; Pennell, K. D. Transport and retention of fullerene nanoparticles in natural soils. J. Environ. Qual. 2010, 39 (6), 1925-1933.

(12) Isaacson, C.; Zhang, W.; Powell, T.; Ma, X.; Bouchard, D. Temporal changes in aqu $/ \mathrm{C}_{60}$ physical-chemical, deposition, and transport characteristics in aqueous systems. Environ. Sci. Technol. 2011, 45 (12), 5170-5177.

(13) Tian, Y.; Gao, B.; Ziegler, K. J. High mobility of SDBS-dispersed single-walled carbon nanotubes in saturated and unsaturated porous media. J. Hazard. Mater. 2011, 186 (2-3), 1766-1772.

(14) Liu, X.; O’Carroll, D. M.; Petersen, E. J.; Huang, Q. G.; Anderson, C. L. Mobility of multiwalled carbon nanotubes in porous media. Environ. Sci. Technol. 2009, 43 (21), 8153-8158.

(15) Jaisi, D. P.; Saleh, N. B.; Blake, R. E.; Elimelech, M. Transport of single-walled carbon nanotubes in porous media: Filtration mechanisms and reversibility. Environ. Sci. Technol. 2008, 42 (22), 8317-8323.

(16) Jaisi, D. P.; Elimelech, M. Single-walled carbon nanotubes exhibit limited transport in soil columns. Environ. Sci. Technol. 2009, 43 (24), 9161-9166.

(17) Li, Z.; Sahle-Demessie, E.; Hassan, A. A.; Sorial, G. A. Transport and deposition of $\mathrm{CeO}_{2}$ nanoparticles in water-saturated porous media. Water Res. 2011, 45 (15), 4409-4418.

(18) Chowdhury, I.; Hong, Y.; Honda, R. J.; Walker, S. L. Mechanisms of $\mathrm{TiO}_{2}$ nanoparticle transport in porous media: Role of solution chemistry, nanoparticle concentration, and flowrate. J. Colloid Interface Sci. 2011, 360 (2), 548-555.

(19) Liu, X. Y.; Chen, G. X.; Su, C. M. Effects of material properties on sedimentation and aggregation of titanium dioxide nanoparticles of anatase and rutile in the aqueous phase. J. Colloid Interface Sci. 2011, 363, 84-91.

(20) Godinez, I. G.; Darnault, C. J. Aggregation and transport of nano$\mathrm{TiO}_{2}$ in saturated porous media: Effects of $\mathrm{pH}$, surfactants and flow velocity. Water Res. 2011, 45 (2), 839-851.

(21) Chen, G. X.; Liu, X. Y.; Su, C. M. Transport and retention of $\mathrm{TiO}_{2}$ rutile nanoparticles in saturated porous media under low-ionic-strength conditions: Measurements and mechanisms. Langmuir 2011, 27 (9), $5393-5402$.

(22) Lecoanet, H. F.; Bottero, J. Y.; Wiesner, M. R. Laboratory assessment of the mobility of nanomaterials in porous media. Environ. Sci. Technol. 2004, 38 (19), 5164-5169.

(23) Guzman, K. A. D.; Finnegan, M. P.; Banfield, J. F. Influence of surface potential on aggregation and transport of titania nanoparticles. Environ. Sci. Technol. 2006, 40 (24), 7688-7693.

(24) Fang, J.; Shan, X. Q.; Wen, B.; Lin, J. M.; Owens, G. Stability of titania nanoparticles in soil suspensions and transport in saturated homogeneous soil columns. Environ. Pollut. 2009, 157 (4), 1101-1109.

(25) Joo, S. H.; Al-Abed, S. R.; Luxton, T. Influence of carboxymethyl cellulose for the transport of titanium dioxide nanoparticles in clean silica and mineral-coated sands. Environ. Sci. Technol. 2009, 43 (13), 4954-4959.

(26) Aiken, G. R.; Hsu-Kim, H.; Ryan, J. N. Influence of dissolved organic matter on the environmental fate of metals, nanoparticles, and colloids. Environ. Sci. Technol. 2011, 45 (8), 3196-3201.

(27) Petosa, A. R.; Jaisi, D. P.; Quevedo, I. R.; Elimelech, M.; Tufenkji, $\mathrm{N}$. Aggregation and deposition of engineered nanomaterials in aquatic environments: Role of physicochemical interactions. Environ. Sci. Technol. 2010, 44 (17), 6532-6549.
(28) Darlington, T. K.; Neigh, A. M.; Spencer, M. T.; Nguyen, O. T.; Oldenburg, S. J. Nanoparticle characteristics affecting environmental fate and transport through soil. Environ. Toxicol. Chem. 2009, 28 (6), 1191-1199.

(29) Pelley, A. J.; Tufenkji, N. Effect of particle size and natural organic matter on the migration of nano- and microscale latex particles in saturated porous media. J. Colloid Interface Sci. 2008, 321 (1), 74-83.

(30) He, Y. T.; Wan, J. M.; Tokunaga, T. Kinetic stability of hematite nanoparticles: The effect of particle sizes. J. Nanopart. Res. 2008, 10 (2), 321-332.

(31) Phenrat, T.; Kim, H. J.; Fagerlund, F.; Illangasekare, T.; Tilton, R. D.; Lowry, G. V. Particle size distribution, concentration, and magnetic attraction affect transport of polymer-modified $\mathrm{Fe}^{0}$ nanoparticles in sand columns. Environ. Sci. Technol. 2009, 43 (13), 5079-5085.

(32) Solovitch, N.; Labille, J.; Rose, J.; Chaurand, P.; Borschneck, D.; Wiesner, M. R.; Bottero, J. Y. Concurrent aggregation and deposition of $\mathrm{TiO}_{2}$ nanoparticles in a sandy porous media. Environ. Sci. Technol. 2010, 44 (13), 4897-4902.

(33) Auffan, M.; Rose, J.; Bottero, J. Y.; Lowry, G. V.; Jolivet, J. P.; Wiesner, M. R. Towards a definition of inorganic nanoparticles from an environmental, health and safety perspective. Nat. Nanotech. 2009, 4 (10), 634-641.

(34) Zhang, W.; Morales, V. L.; Cakmak, M. E.; Salvucci, A. E.; Geohring, L. D.; Hay, A. G.; Parlange, J. Y.; Steenhuis, T. S. Colloid transport and retention in unsaturated porous media: Effect of colloid input concentration. Environ. Sci. Technol. 2010, 44 (13), 4965-4972.

(35) Camesano, T. A.; Logan, B. E. Influence of fluid velocity and cell concentration on the transport of motile and nonmotile bacteria in porous media. Environ. Sci. Technol. 1998, 32 (11), 1699-1708.

(36) Bradford, S. A.; Bettahar, M. Concentration dependent transport of colloids in saturated porous media. J. Contam. Hydrol. 2006, 82 (12), 99-117.

(37) Bradford, S. A.; Kim, H. N.; Haznedaroglu, B. Z.; Torkzaban, S.; Walker, S. L. Coupled factors influencing concentration-dependent colloid transport and retention in saturated porous media. Environ. Sci. Technol. 2009, 43 (18), 6996-7002.

(38) Park, J. Y. Occupational Exposure Assessment for Nanoparticles. Ph.D. Dissertation, University of Minnesota: Minneapolis, MN, 2009.

(39) Park, J. Y.; Ramachandran, G.; Raynor, P. C.; Eberly, L. E.; Olson, G. Comparing exposure zones by different exposure metrics using statistical parameters: Contrast and precision. Ann. Occup. Hyg. 2010, 54 (7), 799-812.

(40) Simon-Deckers, A.; Loo, S.; Mayne-L'Hermite, M.; HerlinBoime, N.; Menguy, N.; Reynaud, C.; Gouget, B.; Carriere, M. Size-, composition- and shape-dependent toxicological impact of metal oxide nanoparticles and carbon nanotubes toward bacteria. Environ. Sci. Technol. 2009, 43 (21), 8423-8429.

(41) Jones, N.; Ray, B.; Ranjit, K. T.; Manna, A. C. Antibacterial activity of $\mathrm{ZnO}$ nanoparticle suspensions on a broad spectrum of microorganisms. FEMS Microbiol. Lett. 2008, 279 (1), 71-76.

(42) Nair, S.; Sasidharan, A.; Rani, V. V. D.; Menon, D.; Nair, S.; Manzoor, K.; Raina, S. Role of size scale of $\mathrm{ZnO}$ nanoparticles and microparticles on toxicity toward bacteria and osteoblast cancer cells. J. Mater. Sci.: Mater. Med. 2009, 20, S235-S241.

(43) Yao, K. M.; Habibian, M. M.; Omelia, C. R. Water and waste water filtration: Concepts and applications. Environ. Sci. Technol. 1971, 5 (11), $1105-1112$.

(44) Derjaguin, B. V.; Landau, L. D. Theory of the stability of strongly charged lyophobic sols and of the adhesion of strongly charged particles in solutions of electrolytes. Acta Physicochim. URSS 1941, 14, 633-662.

(45) Verwey, E. J. W.; Overbeek, J. T. G. Theory of the Stability of Lyophobic Colloids; Elsevier: Amsterdam, Netherlands, 1948.

(46) Lin, S. H.; Cheng, Y. W.; Bobcombe, Y.; Jones, K. L.; Liu, J.; Wiesner, M. R. Deposition of silver nanoparticles in geochemically heterogeneous porous media: Predicting affinity from surface composition analysis. Environ. Sci. Technol. 2011, 45 (12), 5209-5215.

(47) Fatisson, J.; Domingos, R. F.; Wilkinson, K. J.; Tufenkji, N. Deposition of $\mathrm{TiO}_{2}$ nanoparticles onto silica measured using a quartz 
crystal microbalance with dissipation monitoring. Langmuir 2009, 25 (11), 6062-6069.

(48) Fatisson, J.; Ghoshal, S.; Tufenkji, N. Deposition of carboxymethylcellulose-coated zero-valent iron nanoparticles onto silica: Roles of solution chemistry and organic molecules. Langmuir 2010, 26 (15), 12832-12840.

(49) Hong, Y. S.; Honda, R. J.; Myung, N. V.; Walker, S. L. Transport of iron-based nanoparticles: Role of magnetic properties. Environ. Sci. Technol. 2009, 43 (23), 8834-8839.

(50) Liu, X. Y.; Wazne, M.; Christodoulatos, C.; Jasinkiewicz, K. L. Aggregation and deposition behavior of boron nanoparticles in porous media. J. Colloid Interface Sci. 2009, 330 (1), 90-96.

(51) Hogg, R.; Healy, T. W.; Fuerstenau, D. W. Mutual coagulation of colloidal dispersions. Trans. Faraday Soc. 1966, 62, 1638-1651.

(52) Elimelech, M.; Gregory, J.; Jia, X.; Williams, R. A. Particle Deposition and Aggregation: Measurement, Modelling, and Simulation; Butterworth-Heinemann: Oxford, UK, 1995.

(53) Kallay, N.; Zalac, S. Stability of nanodispersions: A model for kinetics of aggregation of nanoparticles. J. Colloid Interface Sci. 2002, 253 (1), 70-76.

(54) Zhang, Y.; Chen, Y. S.; Westerhoff, P.; Hristovski, K.; Crittenden, J. C. Stability of commercial metal oxide nanoparticles in water. Water Res. 2008, 42 (8-9), 2204-2212.

(55) Jarvie, H. P.; Al-Obaidi, H.; King, S. M.; Bowes, M. J.; Lawrence, M. J.; Drake, A. F.; Green, M. A.; Dobson, P. J. Fate of silica nanoparticles in simulated primary wastewater treatment. Environ. Sci. Technol. 2009, 43 (22), 8622-8628.

(56) Zhuang, J.; Qi, J.; Jin, Y. Retention and transport of amphiphilic colloids under unsaturated flow conditions: Effect of particle size and surface property. Environ. Sci. Technol. 2005, 39 (20), 7853-7859.

(57) Attinti, R.; Wei, J.; Kniel, K.; Sims, J. T.; Jin, Y. Virus' (MS2, phi $\mathrm{X} 174$, and Aichi) attachment on sand measured by atomic force microscopy and their transport through sand columns. Environ. Sci. Technol. 2010, 44 (7), 2426-2432.

(58) Hunter, R. J. Zeta Potential in Colloid Science: Principles and Applications; Academic Press: London, UK, 1981.

(59) Jin, Y.; Chu, Y. J.; Li, Y. S. Virus removal and transport in saturated and unsaturated sand columns. J. Contam. Hydrol. 2000, 43 (2), 111128.

(60) Shen, C. Y.; Li, B. G.; Huang, Y. F.; Jin, Y. Kinetics of coupled primary- and secondary-minimum deposition of colloids under unfavorable chemical conditions. Environ. Sci. Technol. 2007, 41 (20), 6976-6982.

(61) Bradford, S. A.; Yates, S. R.; Bettahar, M.; Simunek, J. Physical factors affecting the transport and fate of colloids in saturated porous media. Water Resour. Res. 2002, 38 (12), 1327.

(62) Tufenkji, N.; Elimelech, M. Correlation equation for predicting single-collector efficiency in physicochemical filtration in saturated porous media. Environ. Sci. Technol. 2004, 38 (2), 529-536.

(63) Wang, Y. G.; Li, Y. S.; Fortner, J. D.; Hughes, J. B.; Abriola, L. M.; Pennell, K. D. Transport and retention of nanoscale $\mathrm{C}_{60}$ aggregates in water-saturated porous media. Environ. Sci. Technol. 2008, 42 (10), $3588-3594$.

(64) Song, L.; Elimelech, M. Dynamics of colloid deposition in porous media: Modeling the role of retained particles. Colloids Surf., A 1993, 73, 49-63.

(65) Ko, C. H.; Chen, J. Y. Dynamics of silica colloid deposition and release in packed beds of aminosilane-modified glass beads. Langmuir 2000, 16 (17), 6906-6912.

(66) Ko, C. H.; Elimelech, M. The "shadow effect" in colloid transport and deposition dynamics in granular porous media: Measurements and mechanisms. Environ. Sci. Technol. 2000, 34 (17), 3681-3689.

(67) Johnson, P. R.; Elimelech, M. Dynamics of colloid deposition in porous-media: Blocking based on random sequential adsorption. Langmuir 1995, 11 (3), 801-812.

(68) Shang, J. Y.; Liu, C. X.; Wang, Z. M.; Wu, H.; Zhu, K. K.; Li, J.; Liu, $\mathrm{J}$. In-situ measurements of engineered nanoporous particle transport in saturated porous media. Environ. Sci. Technol. 2010, 44 (21), 81908195.
(69) Bergstrom, L. Hamaker constants of inorganic materials. Adv. Colloid Interface Sci. 1997, 70, 125-169.

(70) Loux, N. T.; Savage, N. An assessment of the fate of metal oxide nanomaterials in porous media. Water, Air, Soil Pollut. 2008, 194 (1-4), $227-241$.

(71) Bhattacharjee, S.; Elimelech, M. Surface element integration: A novel technique for evaluation of DLVO interaction between a particle and a flat plate. J. Colloid Interface Sci. 1997, 193 (2), 273-285.

(72) Bradford, S. A.; Torkzaban, S. Colloid transport and retention in unsaturated porous media: A review of interface-, collector-, and porescale processes and models. Vadose Zone J. 2008, 7 (2), 667-681.

(73) Hahn, M. W.; O'Melia, C. R. Deposition and reentrainment of Brownian particles in porous media under unfavorable chemical conditions: Some concepts and applications. Environ. Sci. Technol. 2004, 38 (1), 210-220.

(74) Shen, C. Y.; Li, B. G.; Wang, C.; Huang, Y. F.; Jin, Y. Surface roughness effect on deposition of nano- and micro-sized colloids in saturated columns at different solution ionic strengths. Vadose Zone J. 2011, 10 (3), 1071-1081. 